\title{
A Gaming Approach to Enhancing Defense Resource Allocation
}

\author{
Todor Tagarev and Gueorgui Stankov *
}

\section{Summary}

This article describes the approach and the experience of the Defense and Force Management Department at the "G. S. Rakovski" Defense and Staff College in Sofia, Bulgaria in conducting interactive simulations that support decision making on force structure, force development programs, and the respective allocation of resources. The primary purpose of the simulation is to educate students (mostly senior military and civilian MOD personnel) in the intricacies of defense planning and programming in a changing environment, and to provide hands-on experience in defense programming and budgeting. In addition, it allows participants to explore the space of potential policy alternatives, force structuring, and programming decisions, thus serving as a powerful decision-support tool.

\section{Introduction}

In transparent defense management systems, decisions about the allocation of resources-personnel, weapon systems and equipment, infrastructure, and money-are clearly related to policy objectives and priorities. However, the link between policy objectives and resource allocation is not straightforward. Intricate methods and models are used to define requirements, match a given solution to a requirement, aggregate individual solutions, analyze the costs of force structures, and manage the development of the armed forces.

Experienced defense policy makers and planners are aware that even in mature defense planning systems, where the assumption is that rationality in decision making prevails, the provision of transparency is a daunting task. The armed forces are commonly expected to conduct diverse operations and perform a variety of other tasks under conditions that often do not lend to advance clarification. Perceptions and expectations change, on the part of both political leaders and the societies that empower them. It is particularly difficult to predict the amount of money that these actors will be willing to invest in defense, especially in the medium and long term. People and organizations within the defense establishment aggressively compete for their share of the defense budget. And these are only a few among the factors that render the environment

Dr. Todor Tagarev is a Senior Research Fellow at the Bulgarian Academy of Sciences and Head of its Center for Security and Defense Management. Col. Gueorgui Stankov serves at the J6 Directorate of the General Staff of the Bulgarian Armed Forces. At the time of writing this article they were respectively Head and Senior Assistant Professor at the Defense and Force Management Department of “G. S. Rakovski” Defense and Staff College in Sofia. 
in which force development and resource allocation decisions are made one of significant uncertainty. ${ }^{1}$

Yet in a democratic societies decision makers are accountable to the citizens for the way they use limited societal resources to raise and sustain armed forces. Therefore, a student of security and defense matters is expected to understand the principles of defense planning and resource allocation, including the principle of transparency, and to be aware of the need and the methods for preserving transparency under the impact of unforeseen events.

It was with this belief in mind that in 2004 the leadership of the National Security and Defense faculty of the "G.S. Rakovski" Defense and Staff College in Sofia decided to include a game simulating defense planning and resource allocation decision making in the curricula of all of its master's programs and a number of other courses. ${ }^{2}$ A similar game was specially developed for training senior defense civilians and military staff in Ukraine. The game was conducted at the National Defense Academy of Ukraine in Kiev in May 2008, and is judged to be very successful.

This essay presents the game as conducted at the "G.S. Rakovski" Defense and Staff College and briefly describes the supporting computer tool. It then builds on the rich educational experience that the game offered, and provides ideas for how such interactive simulations can be used as a decision-support tool. The concluding portion of the essay emphasizes the usefulness of such decision-making simulations for the development of military and civilian expertise and the advancement of democratic civilmilitary relations.

\section{Goals and Objectives}

The primary goal of the simulation is to educate military and civilian students in the principles of defense planning and program-based defense resource management. It enhances students' understanding of important linkages in defense policy making, force development, and budget planning; provides first-hand experience in the process of linking security and defense policy objectives to program decisions to budget pro-

1 Paul Davis describes this uncertainty as "massive" and "ubiquitous." For details refer to Paul K. Davis, "Lessons from Defense Planning and Analysis for Thinking about Systems of Systems," WR-459-OSD, Prepared for the Symposium on Complex System Engineering (Santa Monica, CA: RAND Corporation, January 2007); Paul K. Davis, "Strategic Planning Amidst Massive Uncertainty in Complex Adaptive Systems: the Case of Defense Planning," in Unifying Themes in Complex Systems, vol. IIIB: New Research, eds. Ali A. Minai and Yaneer Bar-Yam (Berlin: Springer, 2006), 201-14.

2 This decision was made after the presentation of a very successful one-week game in the "G.S. Rakovski" Defense and Staff College at the end of 2003 by the U.S. Institute for Defense Analysis (IDA, www.ida.org). The authors gratefully acknowledge the impetus provided by IDA in 2003 and the permission to use the supporting tools. Since 2004, both the concept for the game and the supporting tools underwent considerable evolution, in which the authors played key roles. Therefore, we bear full responsibility for the text presented herein. 
posals; and allows the students to appreciate the role of key defense policy and planning documents. Furthermore, the simulation increases understanding of the ways uncertainty is accounted for, and trains the students in the application of key mechanisms for the incorporation of changes in the planning environment while preserving the integrity of a defense policy.

The second goal of the game is to provide an exercise in role playing. As a result of the simulation, a participating student is expected to better understand the difference between expert and decision-making roles in designing defense policy, and the particular interactions among variety of stakeholders: civilians and military, political leadership and experts, as well as among staff with different functional responsibilities.

The third goal in the design of the simulation was to provide decision support to defense policy and resource allocation deliberations. The fourth (and final goal) of the game is relevant both to students and decision makers. Based on "best practice" models, the simulation allows students to compare existing and potential future processes of defense resource decision making to current best practices in the field, and to identify important process gaps. ${ }^{3}$ It is further useful in identifying data and information requirements, as well as highlighting the necessary methodological, analytical, and training support required for the efficient implementation of advanced defense planning and resource management. ${ }^{4}$

\section{Approach}

To meet the stated goals (and building on the IDA approach and tools), the team at the Defense and Force Management Department, led by Todor Tagarev, designed an interactive simulation, or game, under the title "Decision making in managing force development." The simulation is conducted with students in the master's programs under the faculty of National Security and Defense, as well as with students drawn from a number of additional post-graduate courses. The game usually runs for four days, with six periods in class each day. ${ }^{5}$ In addition, students are expected to work on game assignments in their time out of class.

3 See Handbook on Long-Term Defense Planning, RTO Technical Report 69 (Paris: NATO Research and Technology Organization, April 2003), available at http://www.rta.nato.int/ Pubs/ RDP.asp?RDP=RTO-TR-069; Guide to Capability-Based Planning, TR-JSA-TP3-22004 (TTTCP Joint Systems and Analysis Group, Technical Panel 3, MORS Workshop, October 2004), available at http://www.mors.org/meetings/cbp/read/TP-3_CBP.pdf; and Todor Tagarev, "Introduction to Program-based Defense Resource Management," Connections: The Quarterly Journal 5:1 (Spring-Summer 2006): 55-69, available at https://consortium.pims.org/introduction-to-program-based-defense-resource-management-0.

4 The first two of the goals are educational. The latter two were addressed within project SfP 981149 "Operations Research Support to Force and Operations Planning in the New Security Environment," financed partially by the NATO Science for Peace program.

5 Alternatively, the game may be conducted over three days, with eight periods in class per day. One class period equals forty-five minutes. Thus, the game includes eighteen hours of total class time. 


\section{Structure}

The game is based on the security, economic, and social environment and policies of an imaginary country, with a notional organization of decision-making bodies and a typical armed forces structure. It is organized in nine blocks: an introductory block, seven interactive sessions, and a concluding block with a discussion on practical challenges. In the interactive sessions, in working groups of six to ten students, game participants are asked to:

- Analyze the security and social environment and reach an agreement on defense policy objectives and priorities

- Analyze planning scenarios and derive capability requirements

- Agree on a draft defense programming guidance

- Design force development programs

- Make program decisions and propose a "Program Decision Memorandum"

- Discuss and propose a defense budget

- Propose changes in force development during budget execution and assess the impact on the level of defense capabilities.

This structuring of the game in sessions (or process phases, as presented in Figure 1) roughly emulates current best practices in defense policy making, programming, and budgeting. ${ }^{6}$ One major difference is that the design of force development programs and the program decisions are included in the process of deciding on future force structures. One of the reasons for this - one that is commonly acknowledged in the defense planning community - is that whether or not a future force structure is affordable and achievable depends to a great extent on the force's current situation (force size, operational engagements, legacy systems and their remaining life time). Another reason that is particularly salient for Bulgaria and other countries with immature defense institutions and defense planning and financial management mechanisms is that standing long-term defense plans - although sanctioned at the highest governmental level-are often unaffordable. ${ }^{7}$ What makes such cases even more complicated is that defense ministries sign procurement contracts not according to programs, constrained by official budget forecasts, but in response to requirements in long-term plans, while additional procurement cases and other resource-intensive proposals are pushed through the decision pipeline. A third reason is simple practicality — such simplification permits in-

6 For details, see Todor Tagarev, "The Art of Shaping Defense Policy: Scope, Components, Relationships (but no Algorithms)," Connections: The Quarterly Journal 5:1 (Spring-Summer 2006): 15-34, available at https://consortium.pims.org/the-art-of-shaping-defensepolicy-scope-components-relationships-but-no-algorithms; and Todor Tagarev, "Introduction to Program-based Defense Resource Management."

7 See, for example, Bulgaria's "Plan for Organizational Development and Modernization of the Armed Forces till 2015," approved by the Council of Ministers with Ordnance \# 301 of 2004, State Gazette 103 (November 2004). 


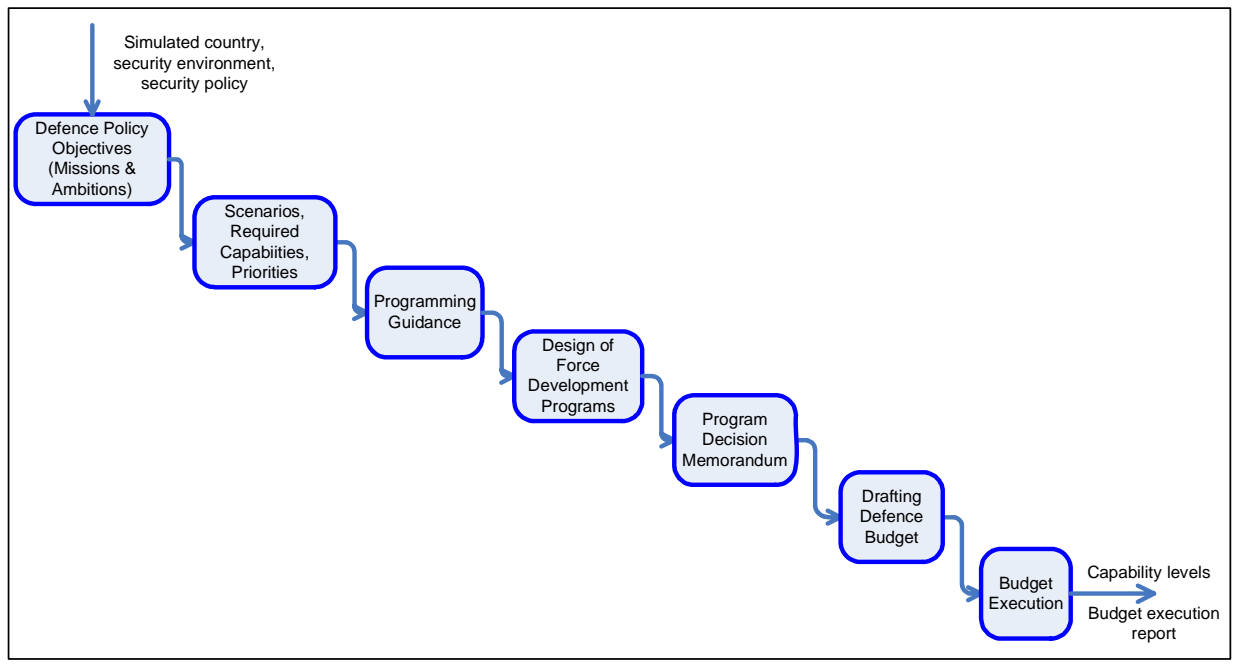

Figure 1: The Process of Defense Resource Allocation Used in the Simulation.

structors to shorten the duration of the game. Other simplifications are described below.

At the end of each session, the working groups report to a plenary group. Thus, game participants are aware of and can compare alternative views. They are also tasked to identify the advantages and disadvantages of selected alternatives.

\section{Roles}

During the interactive sessions, game participants play roles. Depending on the session, each working group acts as:

- Defense Council in interactive session 1

- Defense Requirements Council in interactive session 2

- Programming Council in interactive sessions 3, 5,6 and 7

- Program Teams in interactive session 4.

Such advisory bodies and program teams really exist in the defense establishment of Bulgaria, which makes it easier for an experienced defense practitioner to associate himself or herself with a given role - such as Deputy Minister of Defense for policy, personnel, or acquisition; Deputy Chief of the General Staff for Operations; Chief of Staff of the Land Forces, the Air Force, or the Navy, etc. During the game each participant plays two types of roles: one that is close to his or her background (e.g., a military officer plays the role of a flag officer) and one that is atypical (e.g., an officer playing the role of a civilian deputy minister). This approach enables the leaders of the simulation to make the game rather realistic. Approximately half the members of a simulated advisory body have relevant expertise and contribute to informed decision 
making, while often bringing with them the views typical of and the loyalties implicit to a particular defense organization. At the same time, each participant has the opportunity to get within the skin of someone on the "other side," to understand what drives them and better appreciate their respective rationales.

In the simulation, just like in real life, participants are tasked to act within a rational framework, but the decisions they make collectively reflect the mixture of perceptions, individual experiences and preferences, priorities, and loyalties of the particular students in that group. Since each group has a different combination of participants, with a different set of experiences, the decisions they make are thus inherently subjective.

\section{Coping with Uncertainty}

During the game the participants are forced to adapt previous decisions, plans, and programs to unforeseen events or other changes in the environment, just like leaders of the defense establishment in real life. In each realization of the simulation we prefer to use events that are clearly related to current hot-button issues. The following are among the events most often used in simulations:

- The international community decides to intervene in a conflict region and the country decides to contribute, perhaps deploying a battalion-size unit to an allied force or a coalition. The approved defense budget did not foresee such an operation, and the decision of the parliament to send troops abroad does not provide for additional financing. Therefore, the cost of the unforeseen participation has to be covered within the defense budget.

- A natural disaster occurs, such as a flood, massive forest fire, or earthquake. In response, the government decides to finance certain activities in order to alleviate the negative consequences to the population. Part of that financing is from the previously forecasted (or, depending on the game phase, approved) defense budget.

- The Minister of Defense decides to make an expensive procurement-e.g., to buy a ship — within the budget-planning phase or within budget execution, while such procurement is not included in the respective defense program.

- An accident in a depot where surplus ammunition is stored leads to casualties among the civilian population, and the government decides to speed up the process of utilization (without providing any addition to the defense budget).

- The economic and financial environment during budget implementation differs considerably from the one anticipated during planning and programming, for example:

- The real rate of inflation is twice the forecasted one

- The dollar value of the national currency increases (or drops), while payments on signed contracts are to be made in dollars

- The price of fuel increases dramatically, thus raising the cost of training programs 


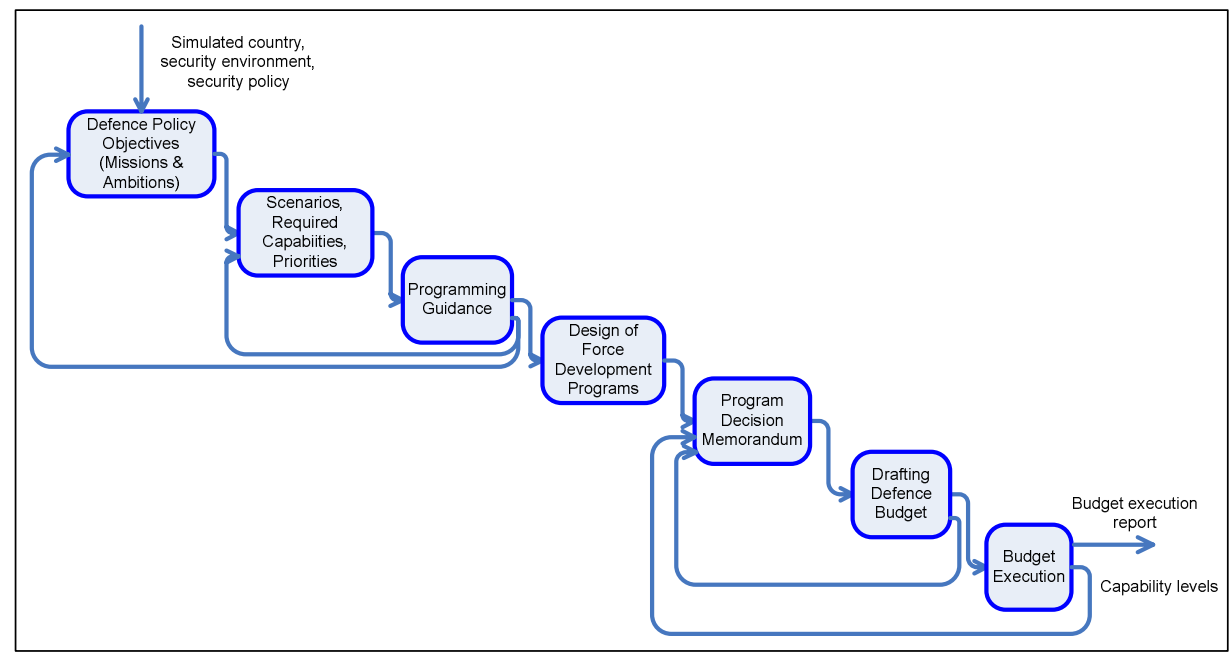

Figure 2: Relating Objectives, Force Structure, and Program and Budget Decisions in a Changing Force Development Environment.

o The labor market becomes more competitive, and military salaries need to be increased in order to meet recruitment targets.

Such events may be introduced in any of the interactive sessions, and are always introduced in sessions six and seven.

Game participants are then tasked to find affordable solutions while still preserving the transparency of the linkages from security objectives to missions and defense ambitions to capability requirements and force structure to defense activities and capability levels. In practice, the players are able to search for only a limited number of solutions, using the feedback loops presented in Figure 2.

\section{Supporting Computer Tool}

The conduct of the game is supported by a computer tool, which is a spreadsheet in Microsoft Excel. The tool automates all calculations, including costing, as well as the transition from program costs to budget. Relevant to the concept of the simulations, the tool is simple and realistic, allowing participants to keep their focus on the main issues and leverages in force structuring and programming, namely:

- Personnel levels

- Percentage of conscripts among the enlisted personnel

- Level of training

- Major procurement projects

- Disposal of excess equipment and infrastructure 
- Planned contributions to operations.

The tool automatically sums up data from all programs, immediately visualizing the main defense planning parameters. For example, it aggregates (potential) budget requests, highlighting the difference between the cost of all programs and the fiscal guidance. In addition, the tool allows a straightforward merging of programmatic information from different sources - for example, of programs developed by two or more working groups. The computer tool provides for reasonable protection of the model structure and the built-in data from unauthorized interference by students. Thus, only instructors can make changes in the program structure, costing factors, elements with an impact on the fiscal guidance, and other essential features. Finally, the use of commercial-off-the-shelf software such as Excel spreadsheets is considered an efficient approach to the simulation, as there are no special requirements for software licenses, installation and maintenance competencies, etc.

\section{Using the Simulation as a Decision Support Tool}

Over the last five years the simulation has proved to be one of the most effective ways to educate students in the complexities of defense policy making, planning, and resource management. For mid-career officers and civilians, as well as for new political appointees in Bulgaria's Ministry of Defense, it is particularly useful in revisiting major factors and clarifying relationships in setting defense policy and plans, translating policy objectives into budget decisions, and reiterating the need for a rational and transparent decision making process. In addition, it is a promising tool to support the process of defense policy making and planning, and has already been used in this capacity (albeit with limited objectives).

Such interactive simulations with decision makers, people playing particular roles, or a mix of participants can be used to discuss and rationalize the major "dimensions" of defense policy - ambitions, operations, manpower policy, technological level and defense industrial ambitions, budget levels, etc. - and rationalize the process of prioritization. It can be further used to generate rough approximations of qualitatively different force structure alternatives, and thus quickly explore the space of viable force structures. With such alternatives in place, game participants may define and discuss the pros and cons of force structures that are considered acceptable and can be sustained within anticipated defense budget levels. Given a change in the force development environment - the necessity to meet urgent and unforeseen requirements, macroeconomic parameters that differ significantly from the ones used during programming and budget planning, etc.- - the simulation can support the generation, analysis, and selection of new program alternatives, reflecting the consequent changes in budget, readiness levels, procurement plans, etc. (We would add a note of caution: it should not be expected that such an approach will result in detailed, meticulously costed force structures and programs that can be turned directly into force development, budgeting, or procurement decisions. While the simulation can be helpful as a decision support tool, it is not intended to produce defense policy fully-formed). 
On two occasions in 2007, senior Bulgarian defense officials (including a deputy minister of defense, and directors and department heads from the defense ministry) participated in simulations conducted by the Defense and Force Management Department with mixed groups of senior officers and civilian students. Decision makers listened to and analyzed working group reports during plenary sessions. The main focus in these cases was on:

- $\quad$ Structuring and defining defense ambitions

- Establishing alternative approaches to partitioning defense capabilities, in particular the way in which alternative representations of capabilities are perceived

- Deriving capability requirements from the analysis of planning scenarios. ${ }^{8}$

\section{Conclusion}

Interactive simulations such as the one described in this article can help make complex theories clearer, and present students with the opportunity to apply theoretical principles and approaches, develop critical thinking skills, and provide "a welcome relief from the everyday tasks of reading and preparing for classes." In fields with few absolutes - like that of defense policy making, planning, and resource allocation - participants in a simulation can explore the main issues through experimentation, interacting with and learning from fellow students.

We found the creation of incentives through competition to be of particular value. ${ }^{10}$ Game participants are divided into teams that are permanent throughout the game. All teams report on the same assignment at the end of each interactive session. Although the faculty always claim that there is no "textbook" solution to the assignment, the motivation of students increases throughout the stages of the game, and teams almost without exception try to outperform the others. An additional benefit of this competitive approach is the opportunity it provides to check and compare the validity of the results against the solutions of other teams.

Finally, our experience confirms and reinforces the finding that human gaming is essential in exploratory analysis supporting defense planning amidst massive uncertainty. ${ }^{11}$ Hence, interactive simulations hold the potential to be a powerful tool in support of decision making on defense policy, planning, and resource allocation.

8 At the time these were novel and methodologically challenging issues for policy makers and planners in the Bulgarian Ministry of Defense.

9 Michael D. Kanner, "War and Peace: Simulating Security Decision Making in the Classroom," PS: Political Science \& Politics 40:4 (October 2007): 795-800.

10 For this and other principles involved in using interactive simulations with senior defense personnel, refer to Hari Bucur-Marcu and Cătălin-Marius Târnăcop, "Defense Institution Building: Training in Support of Defense Planning," Connections: The Quarterly Journal 5:1 (Spring-Summer 2006): 103-15.

11 Davis, "Strategic Planning Amidst Massive Uncertainty in Complex Adaptive Systems: The Case of Defense Planning." 


\section{Bibliography}

Bucur-Marcu, Hari, and Cătălin-Marius Târnăcop. "Defense Institution Building: Training in Support of Defense Planning." Connections: The Quarterly Journal 5, no. 1 (2006): 103-115.

Davis, Paul K.. "Strategic Planning Amidst Massive Uncertainty in Complex Adaptive Systems: the Case of Defense Planning." Unifying Themes in Complex Systems IIIB (2006): 201-214.

Davis, Paul K.. Handbook on Long-Term Defense Planning In RTO Technical Report. Paris: NATO Research and Technology Organization, 2003.

Davis, Paul K.. Lessons from Defense Planning and Analysis for Thinking about Systems of Systems In Complex System Engineering., 2007.

Kanner, Michael D.. "War and Peace: Simulating Security Decision Making in the Classroom." PS: Political Science \& Politics 40, no. 4 (2007): 795-800.

Plan for Organizational Development and Modernization of the Armed Forces till 2015. State Gazette (2004).

Program, The Technical. Guide to Capability-Based Planning. Alexandria, VA: The Technical Cooperation Program, 2004.

Tagarev, Todor. "Introduction to Program-based Defense Resource Management." Connections: The Quarterly Journal 5, no. 1 (2006): 55-69.

Tagarev, Todor. "The Art of Shaping Defense Policy: Scope, Components, Relationships (but no Algorithms)." Connections: The Quarterly Journal 5, no. 1 (2006): 15-34. 